\title{
Mutational characterization of the P3H1/CRTAP/ CypB complex in recessive osteogenesis imperfecta
}

C. Barbirato ${ }^{1,2}$, M. Trancozo ${ }^{1,2}$, M.G. Almeida ${ }^{1,2}$, L.S. Almeida ${ }^{1,2}$, T.O. Santos ${ }^{1}$, J.C.G. Duarte ${ }^{1}$, M.R.G.O. Rebouças ${ }^{3}$, V. Sipolatti ${ }^{3}$, V.R.R. Nunes ${ }^{3}$ and F. Paula ${ }^{1,2}$

${ }^{1}$ Núcleo de Genética Humana e Molecular, Departamento de Ciências Biológicas, Centro de Ciências Humanas e Naturais, Universidade Federal do Espírito Santo, Vitória, ES, Brasil

2Programa de Pós-Graduação em Biotecnologia, Rede Nordeste de Biotecnologia, Centro de Ciências da Saúde, Universidade Federal do Espírito Santo,

Vitória, ES, Brasil

${ }^{3}$ Hospital Infantil Nossa Senhora da Glória, Vitória, ES, Brasil

Corresponding author: C. Barbirato

E-mail: clarabarbirato@yahoo.com.br

Genet. Mol. Res. 14 (4): 15848-15858 (2015)

Received August 16, 2015

Accepted October 22, 2015

Published December 1, 2015

DOI http://dx.doi.org/10.4238/2015.December.1.36

ABSTRACT. Osteogenesis imperfecta (OI) is a genetic disease characterized by bone deformities and fractures. Most cases are caused by autosomal dominant mutations in the type I collagen genes COL1A1 and COL1A2; however, an increasing number of recessive mutations in other genes have been reported. The LEPRE1, CRTAP, and PPIB genes encode proteins that form the $\mathrm{P} 3 \mathrm{H} 1 / \mathrm{CRTAP} / \mathrm{CypB}$ complex, which is responsible for posttranslational modifications of type I collagen. In general, mutations in these genes lead to severe and lethal phenotypes of recessive OI. Here, we describe sixteen genetic variations detected in LEPRE1, CRTAP, and PPIB from 25 Brazilian patients with OI. Samples were screened for mutations on single-strand conformation polymorphism gels and variants were determined by automated sequencing. Seven variants were detected 
in patients but were absent in control samples. LEPRE1 contained the highest number of variants, including the previously described West African allele (c.1080+1G>T) found in one patient with severe OI as well as a previously undescribed p.Trp675Leu change that is predicted to be disease causing. In CRTAP, one patient carried the c.558A>G homozygous mutation, predicted as disease causing through alteration of a splice site. Genetic variations detected in the PPIB gene are probably not pathogenic due to their localization or because of their synonymous effect. This study enhances our knowledge about the mutational pattern of the LEPRE1, CRTAP, and PPIB genes. In addition, the results strengthen the proposition that LEPRE1 should be the first gene analyzed in mutation detection studies in patients with recessive $\mathrm{OI}$.

Key words: Osteogenesis imperfecta; Mutations; LEPRE1; CRTAP; PPIB

\section{INTRODUCTION}

Osteogenesis imperfecta $(\mathrm{OI})$ is a heterogeneous genetic disorder typically characterized by bone fragility and deformity, recurrent fractures, blue sclera, short stature, and dentinogenesis imperfecta. OI is traditionally classified into types I (mild), II (lethal), III (severe), and IV (moderate) based on clinical and radiological findings (Sillence et al., 1979). However, due to the observation of unique characteristics and the discovery of new genes, recent studies have proposed to classify the disease according to the phenotype and location of the mutations (Forlino et al., 2011; Marini and Blissett, 2013). In general, however, the traditional classification is still used when the patients are not analyzed for genetic mutations.

The majority of cases of $\mathrm{Ol}$ are caused by autosomal dominant mutations in the COL1A1 or COL1A2 genes that code for type I collagen chains, an important structural protein of connective tissues such as bone, skin tendons, and ligaments (Barsh and Byers, 1981; Gajko-Galicka, 2002). In 2012, an autosomal dominant mutation was described in IFITM5, which codes for an osteoblastspecific transmembrane protein that might be related to bone mineralization (Moffatt et al., 2008; Cho et al., 2012; Semler at al., 2012).

In addition, over the past few years, a large number of genes (LEPRE1, CRTAP, PPIB, SERPINH1, FKBP10, SERPINF1, SP7, PLOD2, BMP1, TMEM38B, WNT1, and CREB3L1) have been found to be related to recessive forms of OI (Morello et al., 2006; Cabral et al., 2007; van Dijk et al., 2009; Alanay et al., 2010; Christiansen et al., 2010; Lapunzina et al., 2010; Becker et al., 2011; Martínez-Glez et al., 2011; Puig-Hervás et al., 2012; Shaheen et al., 2012; Fahiminiya et al., 2013; Symoens et al., 2013). In general, mutations in these genes affect processes such as type I collagen posttranslational modification and secretion or bone mineralization and result in severe and lethal OI forms (Dalgleish, 1998).

Most cases of recessive $\mathrm{OI}$ are caused by mutations in LEPRE1, CRTAP, and PPIB, which encode prolyl 3-hydroxylase-1 (P3H1), cartilage-associated protein (CRTAP), and cyclophilin B (CypB), respectively. Together, these proteins form a molecular complex that is responsible for the 3-hydroxylation of a proline residue at position 986 of the type I collagen $\alpha 1$ chains. Prolyl 3-hydroxylation is one of the posttranslational modifications of type I collagen chains that contribute to the proper folding, stability, and secretion of the molecules (Vranka et al., 2004; Cabral et al., 2007). 
In addition to prolyl 3-hydroxylation, the P3H1/CRTAP/CypB complex also functions as a PPlase, being the CypB a peptidyl-prolyl cis-trans isomerase for type I collagen, and as a chaperone, preventing type I collagen chains from forming premature aggregates in the endoplasmic reticulum (Ishikawa et al., 2009).

Despite these recent advances, information regarding the profile of mutations for the majority of genes associated with recessive $\mathrm{Ol}$ is scarce. The mutational characterization and the description of non-pathogenic polymorphisms in genes related to OI are crucial to improve the accuracy of molecular diagnosis and of genetic counseling for $O I$ families. In the present study, we describe sixteen genetic variations in LEPRE1, CRTAP, and PPIB; among these are both polymorphisms and pathogenic mutations, including five novel changes and three mutations predicted as disease causing.

\section{MATERIAL AND METHODS}

\section{Samples}

Clinical data and peripheral blood samples of 25 unrelated patients with OI were collected at the Nossa Senhora da Glória Children's Hospital (HINSG), located in Vitória, a Southeastern city in Brazil. The probands were clinically diagnosed with Ol according to the traditional classification (Sillence et al., 1979). Of these, 12 patients had mild symptoms, seven had severe OI, and six had the moderate form of the disease. In addition, 100 unaffected individuals from the same population voluntarily participated as control samples for the polymorphism analysis. When available, samples from the parents and relatives of the patients were also collected and analyzed.

This study was approved by the Research Ethics Committee of the Nossa Senhora da Glória Children's Hospital and written informed consent was obtained from all participants.

\section{Molecular analysis}

DNA was extracted from peripheral blood cells using the methodology described by Miller et al. (1988). Fragments containing the fifteen exons of LEPRE1, the seven exons of CRTAP, the five exons of $P P I B$, and their exon-intron boundaries were amplified by polymerase chain reaction (PCR) in an Applied Biosystems Veriti ${ }^{\circledR}$ 96-Well thermal cycler (Foster City, CA, USA). Primer sequences are presented in Tables 1-3. All fragments were shorter than $400 \mathrm{bp}$. PCR products were screened for mutations by single-strand conformation polymorphism (SSCP) on 5 and $7 \%$ polyacrylamide:5\% glycerol gels and on 6\% glycerol MDE (Cambrex Bio Science Rockland, Inc., Rockland, ME, USA) gels (Orita et al., 1989; Spinardi et al., 1991). Fragments showing abnormal migration patterns were sequenced to detect the variation in the patient DNA sequences when compared with the National Center for Biotechnology Information (NCBI) reference sequences NG_008123.1, NG_008122.1, and NG_012979.1 (for LEPRE1, CRTAP, and PPIB, respectively) and with mutations described in The Human Collagen Mutation Database (Dalgleish, 1998). Sanger sequencing for all exons of the LEPRE1 gene was performed in two patients to find a possible second causative mutation.

In previous studies, the COL1A1 and COL1A2 genes of the patients analyzed in this study were analyzed through SSCP screening and automated sequencing and no mutations were detected. 
Table 1. Primer sequences for PCR amplification of exons and exon/intron boundaries of the LEPRE1 gene.

\begin{tabular}{|c|c|c|c|}
\hline Exon & Fragment size (bp) & Primer & Primer sequences $\left(5^{\prime}-3^{\prime}\right)$ \\
\hline \multirow[t]{2}{*}{$1 \mathrm{~A}$} & 378 & Forward & GGGCTGACTGAAAGGAAAAG \\
\hline & & Reverse & AGCGCAGGCGAAGGGCGC \\
\hline \multirow[t]{2}{*}{ 1B } & 359 & Forward & GGTCCTGAGCATGGAACG \\
\hline & & Reverse & СААСАСТССТСТССССАGAA \\
\hline \multirow[t]{2}{*}{$2^{*}$} & 389 & Forward & CTCAGGGAGGCAGGGATT \\
\hline & & Reverse & AGTCCGGGAATTTGAGGTTAC \\
\hline \multirow[t]{2}{*}{$3^{*}$} & 390 & Forward & ССССТТТССАТССАТААСС \\
\hline & & Reverse & GAGTCCCCATTTATATTATCA \\
\hline \multirow[t]{2}{*}{4} & 378 & Forward & GGGGACTCTTCACССTCATT \\
\hline & & Reverse & AAGCCAAACACCTTGAGGAA \\
\hline \multirow[t]{2}{*}{5} & 297 & Forward & GGTCCCTGGTGCTAGGATTT \\
\hline & & Reverse & GССТАСTССССТСTGСТАСC \\
\hline \multirow[t]{2}{*}{6} & 347 & Forward & CTGGGGAACAGACAGAGAGC \\
\hline & & Reverse & CTCAGCCTCCAGCAAGTTTT \\
\hline \multirow[t]{2}{*}{$7^{*}$} & 239 & Forward & GGCAGCTAGAAGGGACTTAGA \\
\hline & & Reverse & ATGCAGTTTCTTCAAGGTCCTC \\
\hline \multirow[t]{2}{*}{8} & 394 & Forward & AAGCACTTGAGGCTTCCTGA \\
\hline & & Reverse & TCCACTGAACTTGCACCCTA \\
\hline \multirow[t]{2}{*}{$9^{*}$} & 359 & Forward & AAAATGACCTAGCGGGAGA \\
\hline & & Reverse & GGAAGAGGAAGGCGAAGGCTAC \\
\hline \multirow[t]{2}{*}{$10^{*}$} & 347 & Forward & GTGGTAGCCTTCGCCTTC \\
\hline & & Reverse & AАCATAACTCATCСTCGСTTCC \\
\hline \multirow[t]{2}{*}{11} & 378 & Forward & AGGTCCСTTCCACAACACAT \\
\hline & & Reverse & ACATTGGTTCCCCAACTGAA \\
\hline \multirow[t]{2}{*}{12} & 332 & Forward & CATTGGGCATTCCGTAGACT \\
\hline & & Reverse & CCAGTGTGTGTGTGCTAGGG \\
\hline \multirow[t]{2}{*}{13} & 300 & Forward & CACACAAAGCCAСССТССТ \\
\hline & & Reverse & CAAGGGTACCGCCCACTG \\
\hline \multirow[t]{2}{*}{14} & 388 & Forward & GGGAAGCCATACTGAAGAGC \\
\hline & & Reverse & GTGTCCCAAGTGCTCCTTTC \\
\hline \multirow[t]{2}{*}{$15 \mathrm{~A}$} & 384 & Forward & CCTGGGAAGTAGCAGCTGAG \\
\hline & & Reverse & GCACCATGTAGAAGGCTGTG \\
\hline \multirow[t]{2}{*}{ 15B } & 348 & Forward & TGACTAGACCCATGGAGAGGA \\
\hline & & Reverse & AGACCTCTGGGACAGAATGG \\
\hline
\end{tabular}

*Primer sequences used to amplify exons 2, 3, 7, 9, and 10 were described by Baldridge et al., 2008.

Table 2. Primer sequences for PCR amplification of exons and exon/intron boundaries of the CRTAP gene.

\begin{tabular}{|c|c|c|c|}
\hline Exon & Fragment size (bp) & Primer & Primer sequences $\left(5^{\prime}-3^{\prime}\right)$ \\
\hline \multirow[t]{2}{*}{$1 \mathrm{~A}$} & 399 & Forward & CAGCTGGCGCCCAGATCCCC \\
\hline & & Reverse & GCAGCCGCAGGCTGATCTCC \\
\hline \multirow[t]{2}{*}{ 1B } & 391 & Forward & GCCGAGAGCGTGGGCTACCT \\
\hline & & Reverse & GAACTGGAGGGGCAACGCGG \\
\hline \multirow[t]{2}{*}{2} & 392 & Forward & CCTGGAAGTCATGGAACCTT \\
\hline & & Reverse & GCAGCTGCTTATGGAGAGAC \\
\hline \multirow[t]{2}{*}{3} & 333 & Forward & TGGTCTTGGTTCCCTTTGA \\
\hline & & Reverse & AGGCATGCAGGCAGAAAC \\
\hline \multirow[t]{2}{*}{4} & 310 & Forward & CTTTTTCATTTGGGCAGGAC \\
\hline & & Reverse & TGAACTCTCAACAACCGTAGC \\
\hline \multirow[t]{2}{*}{5} & 294 & Forward & TGGCCTTTTTGTTTAGAAGC \\
\hline & & Reverse & AAGGCACGAGGTAGTCTCCA \\
\hline \multirow[t]{2}{*}{6} & 240 & Forward & ССТСССТССТСССАGTTCTA \\
\hline & & Reverse & AGGACTCAGCCTTCCAGTGA \\
\hline \multirow[t]{2}{*}{7} & 238 & Forward & TGATGGCCTCTCGGGATA \\
\hline & & Reverse & GGCTCTGAGGTATCAACAGC \\
\hline
\end{tabular}


Table 3. Primer sequences for PCR amplification of exons and exon/intron boundaries of the PPIB gene.

\begin{tabular}{lcll}
\hline Exon & Fragment size (bp) & Primer & Primer sequences (5'-3') \\
\hline 1 & 259 & Forward & CTTCCGGCCTCAGCTGTC \\
& & Reverse & AGGAGGGGCTCAGCCAAG \\
2 & 283 & Forward & TCTCCCATCCTCAGGTTAGC \\
& & Reverse & CTCTGCAGGTCAGTTTGCTG \\
3 & 293 & Forward & CGAGCAGGAGTTGTGGACTT \\
4 & 314 & Reverse & GAGCTGGGGAGAAAGAGG \\
& & Forward & CGAATGTCTGCTTGGTTTGG \\
5 & 306 & Reverse & AATCCCCGGTGAGATTG \\
& & Forward & TTCTCCTGAGCGTGGAC \\
& & Reverse & CTCCACCAGATGCCAGCAC \\
\hline
\end{tabular}

\section{RESULTS}

SSCP screening of 25 unrelated Brazilian patients with OI and sequencing of the abnormal fragments identified eleven genetic variations in LEPRE1 (Figure 1), three in CRTAP (Figure 2), and two in PPIB (Figure 3).

A
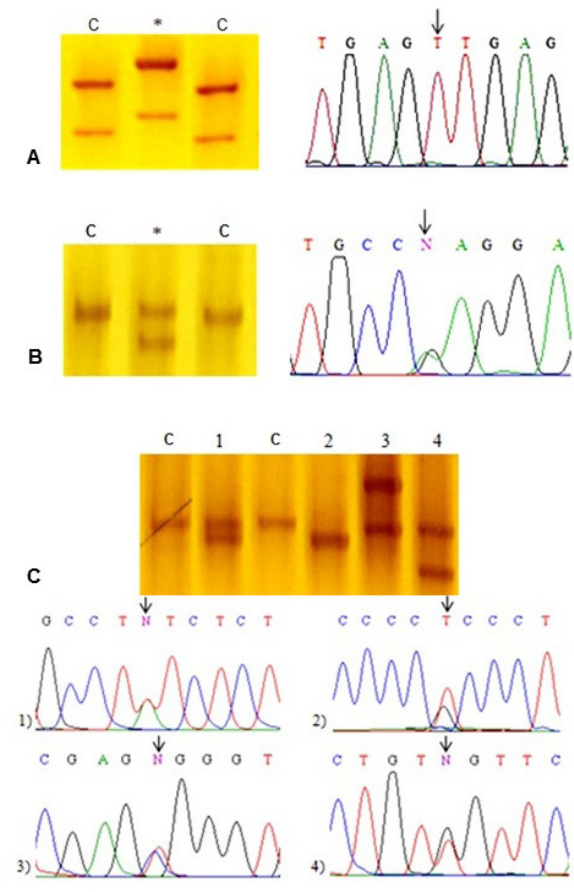

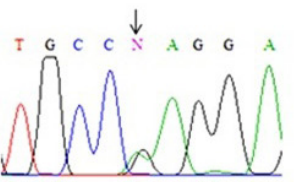

$\mathrm{E}$
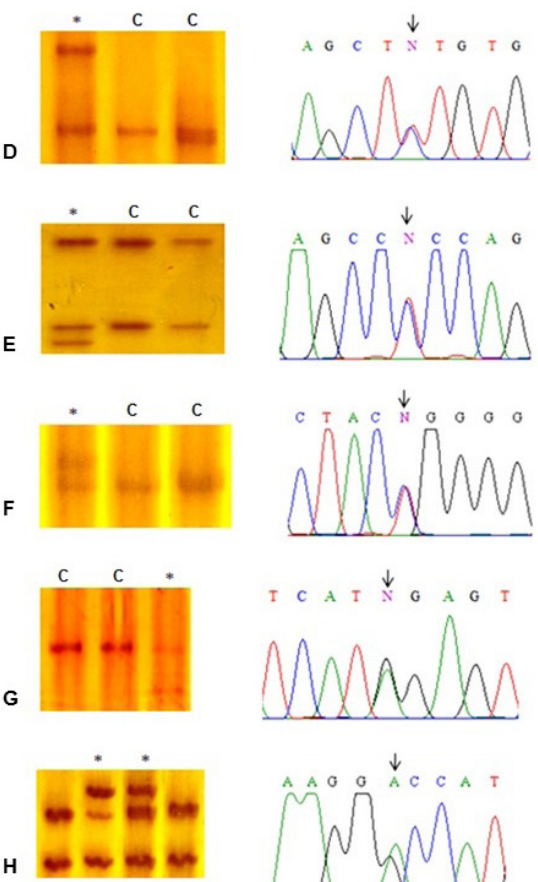
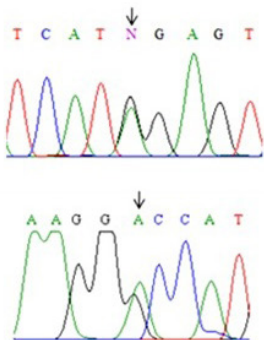

Figure 1. SSCP gels and sequencing of $\angle E P R E 1$ fragments. A. c. $1080+1 \mathrm{G}>T$ detected in patient $P 1$. B. c. 1087A $>\mathrm{G}$ detected in patient P2. C. 1) c. $2055+74 T>A$; 2) c.1915-20T>G; 3) c.2055+17C >T; 4) c.2024G $>T / p$.Trp675Leu detected in patient P3. D. c.1720+52C>T in patient P4. E. c.1812C>T (p.Pro604=) also in patient P4. F. c.1501C >T (p.Arg501Trp). G. c.1647G>A (p.Met549lle). H. c.1839-30G>A. *Abnormal fragments on SSCP gels; "C" corresponds to control samples without the genetic change. The arrows point to the variants in the electropherograms. SSCP = single-strand conformation polymorphism. 

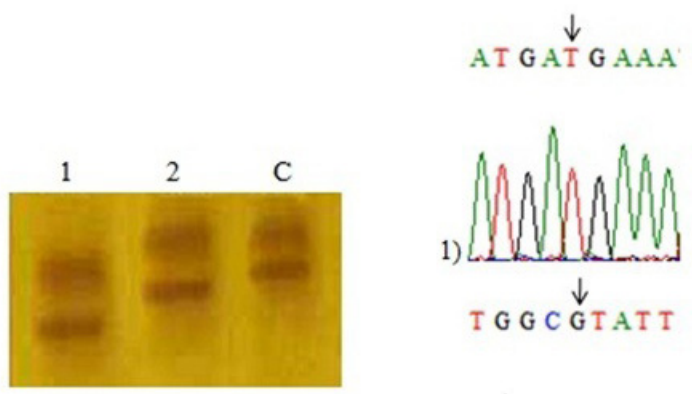

\section{A}

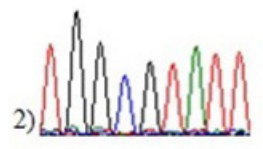

\section{B}

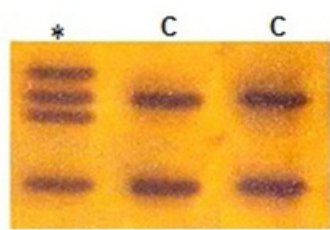

GCTA $\stackrel{\downarrow}{\mathrm{CG}} \mathrm{AGA}$

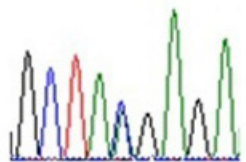

Figure 2. SSCP gels and sequencing of CRTAP fragments. A. 1: c.534C $>T$ (p.Asp174=); 2: c.558A>G (p.Ala186=). B. c. $1152+36 \mathrm{C}>\mathrm{A}$. *Abnormal fragments on SSCP gels; "C" corresponds to control samples without the genetic change. The arrows point to the variants in the electropherograms. SSCP = single-strand conformation polymorphism.

A
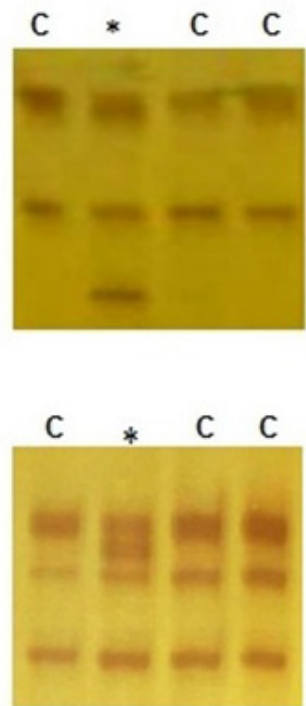
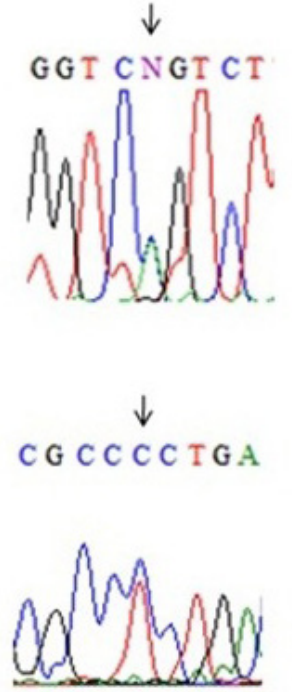

Figure 3. SSCP gels and sequencing of $P P I B$ fragments. A. c.63C $>A$ (p.Ser21=). B. c.344-27C $>$ T. *Abnormal fragments on SSCP gels; "C" corresponds to control samples without the genetic change. The arrows point to the variants in the electropherograms. SSCP $=$ single-strand conformation polymorphism. 


\section{LEPRE1}

In this study, we detected five genetic variations in LEPRE1 in patients with $\mathrm{Ol}$ that were absent in control samples.

One of the patients (P1), diagnosed with OI type III, presented a homozygous splice site mutation (c. $1080+1 \mathrm{G}>\mathrm{T}$ ) (Figure 1A). DNA of relatives was not available. $\mathrm{P} 1$ is son of $a$ consanguineous couple (his parents are cousins) and is the only diagnosed case of OI in his family.

A second patient (P2), also diagnosed with OI type III, presented a heterozygous substitution (c.1087A>G) of the seventh nucleotide in exon 6 , leading to an amino acid change from lysine to glutamic acid (p.Lys363Glu) (Figure 1B). P2 is the only affected patient in his family and his parents reported absence of any consanguinity.

A c.2024G>T/p.Trp675Leu heterozygous mutation, located in exon 14, was detected in a patient with OI type III (P3). The unaffected parents of P3 claimed no consanguinity. DNA from both parents and a younger sister also affected by OI type III was analyzed. The mutation was present in the mother and sister, but was absent in the patient's father (Figure 1C4).

Samples from P2 and P3 were also Sanger sequenced for all exons of the LEPRE1 gene, but a second mutation was not identified in either patient.

Patient P4 presented both c. $1720+52 C>T$ and c. $1812 C>T$ (p.Pro604=) variations, located in intron 11 and exon 12, respectively (Figure 1D and E). P4 and his mother were both affected by OI type I. Analysis of the patient's mother's DNA revealed that she did not carry the variations detected in P4. DNA of the patient's unaffected father was not available for testing.

In addition, six different polymorphisms were detected in the LEPRE1 gene of patients with Ol and in control samples: c.1501C>T (p.Arg501Trp), c.1647G>A (p.Met549lle), c.1839-30G>A, c. 1915-20T>G, c.2055+17C>T, and c.2055+74T>A (Figure 1C, F, G, and H).

\section{CRTAP}

A c. $558 A>G(p . A l a 186=)$ synonymous mutation was detected in a homozygous state in exon 2 of one patient (P5) with OI type IV (Figure 2A2). P5 is the only diagnosed patient with $\mathrm{OI}$ in the family and her parents declared no consanguinity. Two polymorphisms were also detected in patient and control samples: c.534C $>$ T (p.Asp174=) and c.1152+36C $>$ A (Figure $2 \mathrm{~A} 1$ and $\mathrm{C})$.

\section{PPIB}

An intronic mutation (c.344-27C>T) in the heterozygous state was detected in one patient with OI type I (P6) but was absent in the 100 control samples and in the patient's mother (Figure 3B). P6 is the only affected patient in his family and he is the son of a non-consanguineous couple. In addition, one polymorphism in exon 1 (c.63C>A/p.Ser21=) of patients and control samples was detected (Figure 3A).

The allelic frequencies of polymorphisms detected in patients and controls are described in Table 4. A summary of mutations identified in patients with $\mathrm{Ol}$ and absent in 100 control samples is reported in Table 5. 


\begin{tabular}{|c|c|c|c|c|}
\hline Number & Genetic variation & Gene & Localization & Allele frequency* \\
\hline 1 & c. $2055+74 \mathrm{~T}>\mathrm{A}$ & LEPRE1 & Intron 14 & $11.6 \%(29 / 250)$ \\
\hline 2 & c. $2055+17 \mathrm{C}>\mathrm{T}$ & LEPRE1 & Intron 14 & $8.8 \%(22 / 250)$ \\
\hline 3 & c. $1915-20 T>G$ & LEPRE1 & Intron 13 & $9.2 \%(23 / 250)$ \\
\hline 4 & c. $1839-30 G>A$ & LEPRE1 & Intron 12 & $58.4 \%(146 / 250)$ \\
\hline 5 & c. $1647 \mathrm{G}>\mathrm{A}$ (p.Met549lle) & LEPRE1 & Exon 11 & $0.8 \%(2 / 250)$ \\
\hline 6 & c.1501C>T (p.Arg501Trp) & LEPRE1 & Exon 10 & $1.6 \%(4 / 250)$ \\
\hline 7 & c. $534 \mathrm{C}>\mathrm{T}(\mathrm{p} .174 \mathrm{Asp}=)$ & CRTAP & Exon 2 & $12.0 \%(30 / 250)$ \\
\hline 8 & c. $1152+36 C>A$ & CRTAP & Intron 6 & $9.2 \%(23 / 250)$ \\
\hline 9 & c. $63 \mathrm{C}>\mathrm{A}($ p.Ser $21=)$ & $P P I B$ & Exon 1 & $5.2 \%(13 / 250)$ \\
\hline
\end{tabular}

*Allele frequency among all participants, including 25 unrelated patients (50 alleles) and 100 normal controls (200 alleles), totaling 125 Brazilian individuals (250 alleles).

Table 5. Genetic changes detected in patient samples.

\begin{tabular}{|c|c|c|c|c|c|c|c|c|}
\hline & Patient & Mutation & Gene & Zygosity & Type of mutation & Predicted as disease causing & Ol type & Novel or Known \\
\hline 1 & $\mathrm{P} 1$ & c. $1080+1 G>T$ & LEPRE1 & Hom & Splice site & Yes & Severe & Known \\
\hline 2 & $\mathrm{P} 2$ & c.1087A>G (p.Lys363Glu) & LEPRE1 & Het & Missense & No & Severe & Novel \\
\hline 3 & P3 & c.2024G>T (p.Trp675Leu) & LEPRE1 & Het & Missense & Yes & Severe & Novel \\
\hline 4 & P4 & c. $1720+52 C>T$ & LEPRE1 & Het & Intronic & No & Mild & Novel \\
\hline 5 & P4 & c. $1812 C>T$ (p.Pro604=) & LEPRE1 & Het & Synonymous & No & Mild & Novel \\
\hline 6 & P5 & c. $558 \mathrm{~A}>\mathrm{G}(\mathrm{p} . \mathrm{Ala} 186=)$ & CRTAP & Hom & Synonymous* & Yes & Moderate & Novel \\
\hline 7 & P6 & c. $344-27 C>T$ & PPIB & Het & Intronic & No & Mild & Known \\
\hline
\end{tabular}

Hom = homozygous; Het = heterozygous; OI = osteogenesis imperfecta. *Predicted splice site mutation.

\section{DISCUSSION}

In this study, we analyzed 25 unrelated patients with $\mathrm{Ol}$ and identified sixteen different genetic variations in the LEPRE1, CRTAP, and PPIB genes, five of which have not been previously reported. Of the total, 3 mutations were predicted as disease causing. The majority of mutations were located in LEPRE1, whereas the analysis of PPIB did not show pathogenic changes.

Among the variations detected in LEPRE1, we identified the homozygous splice site mutation c. $1080+1 \mathrm{G}>\mathrm{T}$ in a patient (P1) with a severe form of OI. This mutation, detected in one or in both alleles, had already been reported more than 50 times in different studies (Dalgleish, 1998). According to Cabral et al. (2007), who first reported the c. $1080+1 \mathrm{G}>\mathrm{T}$ mutation, the mutant allele had originated in West Africa and was transported to America. The mutation results in altered splicing, leading to premature translational termination and decreased levels of LEPRE1 mRNA. Once the normal production of $\mathrm{P} 3 \mathrm{H} 1$ is reduced, the effect on type I collagen molecules is expected to be damaging.

We detected the c.1087A>G/p.Lys363Glu variation in a heterozygous state in one patient (P2) with OI type III. This mutation had not been reported in the reference databases "Human Collagen Mutation Database 1998" (Dalgleish, 1998) and "Single Nucleotide Polymorphism Database (dbSNP)" (Kitts and Sherry, 2002), both accessed in August 2014. It is known that splice site mutations and amino acid changes might be damaging for protein formation. However, prediction programs suggest that p.Lys363Glu is a benign polymorphism in the European American population (Schwarz et al., 2014).

The c.2024G>T/p.Trp675Leu heterozygous mutation, located in exon 14, was detected in a second patient with OI type III (P3). This patient has unaffected parents and one sister also 
diagnosed with OI. The patient's sister and mother, but not the father, carry the same variation. The p.Trp675Leu mutation is predicted to be disease causing (Schwarz et al., 2014). It results in a change from tryptophan, an aromatic amino acid, to leucine, a nonpolar amino acid, affecting the molecular structure of the protein. The second causative mutation was not detected in the patient, even after sequencing all exons of the LEPRE1 gene. It is possible that the second mutation is located in a non-coding region of LEPRE1 not analyzed in this study.

Patient P4 presented both c. $1720+52 \mathrm{C}>\mathrm{T}$ and c.1812C $>\mathrm{T}$ (p.Pro604=) variations, in intron 11 and exon 12, respectively. Both changes are absent in the patient's affected mother, suggesting that the changes are not the cause of $\mathrm{Ol}$ in $\mathrm{P} 4$. This conclusion is also supported by the location of the intronic change in c. $1720+52 C>T$ and by the synonymous effect of c.1812C>T, which does not lead to an amino acid change (p.Pro604=). In addition, the family history, involving a parent and a child affected by $\mathrm{OI}$, indicates an autosomal dominant pattern, which differs from the expected profile for mutations in LEPRE1.

Six different polymorphisms were detected in the LEPRE1 genes of patients with OI and controls: c. 2055+74T>A, c.2055+17C>T, c. 1915-20T>G, c.1839-30G>A, c.1647G>A (p.Met549lle), and c.1501C>T (p.Arg501Trp). The first four are common intronic variations not associated with Ol. The c.1647G>A (p.Met549lle) variant, despite involving an amino acid change, is described as a benign polymorphism in the African American and in the European American populations. As c.1647G >A (p.Met549lle) was detected in both patient and control samples in the present study, we suggest that it is also a non-pathogenic polymorphism in the Brazilian population. However, the last polymorphism detected (c.1501C>T/p.Arg501Trp) is predicted to be disease causing in the African American and in the European American populations (Schwarz et al., 2014). As it was also detected in control samples in our study, we infer that the pathogenicity occurs when the mutation is in a homozygous state, rather than heterozygous as detected here.

Three genetic changes were detected in CRTAP. A homozygous c.558A>G (p.Ala186=) mutation was detected in one patient (P5) with OI type IV. This mutation, absent in one hundred control samples, is predicted to be disease causing as it alters a splice site (Schwarz et al., 2014). Thus, we suggest that c.558A $>\mathrm{G}$ (p.Ala186=) might be associated with $\mathrm{Ol}$ in this patient.

In addition, a variant inside CRTAP exon 2 that does not lead to an amino acid change (c.534C $>$ T/p. 174Asp=) was detected as well. A previous study reported that this SNP might be associated with differences in bone mineralization. A positive association of the $C$ allele and bone mineralization density in Chinese women has been established (Li et al., 2010). Although it is not probable that this variation is the cause of $\mathrm{Ol}$ as it was also detected in unaffected control samples, we suggest that patients with OI due to another mutation might present different clinical phenotypes in the presence of the c.534C>T polymorphism.

Finally, the variant detected in intron 6 (c.1152+36C>A) of patients and control samples most likely represents a common polymorphism in CRTAP, not associated with OI.

In the PPIB gene, two genetic changes were detected. The c.344-27C>T change is a previously described heterozygous intronic variant with unknown consequences to human phenotypes (Exome Variant Server, accessed August 2014). Because this variation was detected in a non-coding region, we suggest that c.344-27C>T might be a rare genetic change not associated with the development of $\mathrm{OI}$. The second PPIB variant is a single nucleotide substitution that does not change the amino acid (c.63C >A/p.Ser21=). In addition, its presence in unaffected control samples also suggests that it is a non-pathogenic polymorphism.

In addition to $L E P R E 1, C R T A P$, and PPIB, a large number of recessive Ol genes have 
been described. Hence, the patients without identified mutation in this study probably carry causative mutations in other genes related to Ol.

SSCP screening is described as a technique with limited efficiency for mutation detection. However, in this analysis, we improved the sensitivity of the technique by testing each sample on three distinct gels with different polyacrylamide concentrations. Furthermore, all fragments were engineered to be shorter than 400 bp because it is known that in this condition the accuracy of the SSCP technique is improved.

In conclusion, sixteen mutations and polymorphisms in LEPRE1, CRTAP, and PPIB were detected after analysis of 25 patients with OI. It was verified that $L E P R E 1$ is the gene that contains the majority of the genetic alterations (11/16), including both polymorphisms and potentially deleterious mutations. To date, there have been no other descriptions of mutations in the LEPRE1, CRTAP, and $P P I B$ genes in Brazilian samples and this study provides the first information about the mutational pattern of these genes in our population. The results strengthen the proposition that LEPRE1 should be the first gene analyzed in mutation detection studies in patients with recessive $O I$.

\section{Conflicts of interest}

The authors declare no conflict of interest.

\section{ACKNOWLEDGMENTS}

Research supported by ArcelorMittal Tubarão, Fundação de Amparo à Pesquisa do Espírito Santo (FAPES), Fundo de Apoio à Ciência e Tecnologia (FACITEC), Universidade Federal do Espírito Santo (UFES), and Ministério da Ciência, Tecnologia e Inovação/Conselho Nacional de Desenvolvimento Científico e Tecnológico/Ministério da Educação/Coordenação de Aperfeiçoamento de Pessoal de Nível Superior (MCTI/CNPq/MEC/CAPES).

\section{REFERENCES}

Alanay Y, Avaygan H, Camacho N, Utine GE, et al. (2010). Mutations in the gene encoding the RER protein FKBP65 cause autosomal-recessive osteogenesis imperfecta. Am. J. Hum. Genet. 86: 551-559.

Baldridge D, Schwarze U, Morello R, Lennington J, et al. (2008). CRTAP and LEPRE1 mutations in recessive Osteogenesis Imperfecta. Hum. Mutat. 29: 1435-1442.

Barsh GS and Byers PH (1981). Reduced secretion of structurally abnormal type I procollagen in a form of osteogenesis imperfecta. Proc. Nat. Acad. Sci. U. S. A. 78: 5142-5146.

Becker J, Semler O, Gilissen C, Li Y, et al. (2011). Exome sequencing identifies truncating mutations in human SERPINF1 in autosomal-recessive osteogenesis imperfecta. Am. J. Hum. Genet. 88: 362-371.

Cabral WA, Chang W, Barnes AM, Weis M, et al. (2007). Prolyl 3-hydroxylase 1 deficiency causes a recessive metabolic disorder resembling lethal/severe osteogenesis imperfecta. Nat. Genet. 39: 359-365.

Cho TJ, Lee KE, Lee SK, Song SJ, et al. (2012). A single recurrent mutation in the 5'-UTR of IFITM5 causes osteogenesis imperfecta type V. Am. J. Hum. Genet. 91: 343-348.

Christiansen HE, Schwarze U, Pyott SM, AISwaid A, et al. (2010). Homozygosity for a missense mutation in SERPINH1, which encodes the collagen chaperone protein HSP47, results in severe recessive osteogenesis imperfecta. Am. J. Hum. Genet. 86: 389-398.

Dalgleish R (1998). The Human Collagen Mutation Database 1998. Nucleic Acids Res. 26: 253-255. Available at [http://www. le.ac.uk/ge/collagen/]. Accessed August 2014.

Exome Variant Server, NHLBI GO Exome Sequencing Project (ESP) (2014). Available at [http://evs.gs.washington.edu/EVS/]. Accessed August 2014.

Fahiminiya S, Majewski J, Mort J, Moffatt P, et al. (2013). Mutations in WNT1 are a cause of osteogenesis imperfecta. J. Med. Genet. 50: 345-348. 
Forlino A, Cabral WA, Barnes AM and Marini JC (2011). New perspectives on osteogenesis imperfecta. Nat. Rev. Endocrinol. 7: $540-557$

Gajko-Galicka A (2002). Mutations in type I collagen genes resulting in osteogenesis imperfecta in humans. Acta Biochim. Pol. 49: 433-441.

Ishikawa Y, Wirz J, Vranka JA, Nagata K, et al. (2009). Biochemical characterization of the prolyl 3-hydroxylase 1.cartilageassociated protein.cyclophilin B complex. J. Biol. Chem. 284: 17641-17647.

Kitts A and Sherry S (2002). Chapter 5: The Single Nucleotide Polymorphism Database (dbSNP) of nucleotide sequence variation. In: The NCBI Handbook (McEntyre J and Ostell J, eds.). National Center for Biotechnology Information (USA), Bethesda. Available at [http://www.ncbi.nlm.nih.gov/snp/]. Accessed August 2014.

Lapunzina P, Aglan M, Temtamy S, Caparrós-Martín JA, et al. (2010). Identification of a frameshift mutation in Osterix in patient with recessive osteogenesis imperfecta. Am. J. Hum. Genet. 87: 110-114.

$\mathrm{Li}$ GH, Kung AW and Huang QY (2010). Common variants in FLNB/CRTAP, not ARHGEF3 at 3p, are associated with osteoporosis in southern Chinese women. Osteoporos. Int. 21: 1009-1020.

Marini JC and Blissett AR (2013). New genes in bone development: what's new in osteogenesis imperfecta. J. Clin. Endocrin. Metab. 98: 3095-3103.

Martínez-Glez V, Valencia M, Caparrós-Martín JÁ, Aglan M, et al. (2011). Identification of a mutation causing deficient BMP1/ mTLD proteolytic activity in autosomal recessive osteogenesis imperfecta. Hum. Mutat. 33: 343-350.

Miller SA, Dykes DD and Polesky HF (1988). A simple salting out procedure for extracting DNA from human nucleated cells. Nucleic Acids Res. 16: 1215.

Moffatt P, Gaumond MH, Salois P, Sellin K, et al. (2008). Bril: a novel bone-specific modulator of mineralization. J. Bone Miner. Res. 23: 1497-1508.

Morello R, Bertin TK, Chen Y, Hicks J, et al. (2006). CRTAP is required for prolyl 3-hydroxylation and mutations cause recessive osteogenesis imperfecta. Cell 127: 291-304.

Orita M, Iwahana H, Kanazawa H, Hayashi K, et al. (1989). Detection of polymorphisms of human DNA by gel electrophoresis as single-stranded conformation polymorphisms. Proc. Nat. Acad. Sci. U. S. A. 86: 2766-2770.

Puig-Hervás MT, Temtamy S, Aglan M, Valencia M, et al. (2012). Mutations in PLOD2 cause autosomal-recessive connective tissue disorders within the Bruck Syndrome - osteogenesis imperfecta phenotypic spectrum. Hum. Mutat. 33: 1444-1449.

Schwarz JM, Cooper DN, Schuelke M and Seelow D (2014). MutationTaster2: mutation prediction for the deep-sequencing age. Nat. Methods 11: 361-362.

Semler O, Garbes L, Keupp K, Swan D, et al. (2012). A mutation in the 5'-UTR of IFITM5 creates an in-frame start codon and causes autosomal-dominant osteogenesis imperfecta type $\vee$ with hyperplastic callus. Am. J. Hum. Genet. 91: 349-357.

Shaheen R, Alazami AM, Alshammari MJ, Faqeih E, et al. (2012). Study of autosomal recessive osteogenesis imperfecta in Arabia reveals a novel locus defined by TMEM38B mutation. J. Med. Genet. 49: 630-635.

Sillence DO, Senn A and Danks DM (1979). Genetic heterogeneity in osteogenesis imperfecta. J. Med. Genet. 16: 101-116.

Spinardi L, Mazars R and Theillet C (1991). Protocols for an improved detection of point mutations by SSCP. Nucleic Acids Res. 19: 4009.

Symoens S, Malfait F, D'hondt S, Callewaert B, et al. (2013). Deficiency for the ER-stress transducer OASIS causes severe recessive osteogenesis imperfect in humans. Orphanet. J. Rare Dis. 8: 154.

van Dijk FS, Nesbitt IM, Zwikstra EH, Nikkels PG, et al. (2009). PPIB mutations cause severe osteogenesis imperfecta. Am. J. Hum. Genet. 85: 521-527.

Vranka JA, Sakai LY and Bächinger HP (2004). Prolyl 3-hydroxylase 1, enzyme characterization and identification of a novel family of enzymes. J. Biol. Chem. 279: 23615-23621. 